\title{
TITLE:
}

\section{Analysis of Japan's post-Fukushima energy strategy}

AUTHOR(S):

McLellan, Benjamin C.; Zhang, Qi; Utama, N. Agya;

Farzaneh, Hooman; Ishihara, Keiichi N.

CITATION:

McLellan, Benjamin C....[et al]. Analysis of Japan's post-Fukushima

energy strategy. Energy Strategy Reviews 2013, 2(2): 190-198

ISSUE DATE:

2013-09

URL:

http://hdl.handle.net/2433/179314

RIGHT:

(c) 2013 Elsevier Ltd.; この論文は出版社版でありません。引用の際には 出版社版をご確認ご利用ください。; This is not the published version. Please cite only the published version. 


\section{Analysis of Japan's post-Fukushima}

\section{energy strategy}

Benjamin C. McLellan ${ }^{1}$

Graduate School of Energy Science, Kyoto University, Yoshida-honmachi, Sakyo-ku, Kyoto 606-8501, Japan.

E-mail: b-mclellan@energy.kyoto-u.ac.jp

Tel.: +81757539173

Fax: +81757534775

Qi Zhang

E-mail: zhangqi@energy.kyoto-u.ac.jp

N.Agya Utama

E-mail: utama.nukiagya.4c@kyoto-u.ac.jp

Hooman Farzaneh

E-mail: hooman.farzaneh.2v@kyoto-u.ac.jp

Keiichi N. Ishihara

E-mail: ishihara@energy.kyoto-u.ac.jp

${ }^{1}$ Corresponding author contact details: E-mail: b-mclellan@energy.kyoto-u.ac.jp Tel.: +81757539173 Fax: +81 757534775 


\begin{abstract}
In post-Fukushima Japan, the government has presented three scenarios of nuclear power reduction (zero nuclear, 15\% nuclear, and 20-25\% nuclear), of which it has recently selected the zero nuclear energy scenario as its preferred option. The choice of energy strategy has significant implications for the Asian region as well as domestically. This paper examines these scenarios and the energy strategy as a whole with regards to its achievability and outcomes. The analysis is based on modeling of the existing energy system of Japan with projections based on the government strategy out to the 2030's. Under all the scenarios, it is likely that a small increase in energy security will be obtained, but the achievement of environmental commitments is less likely. The paper points out that, while largely internally consistent, the government's strategy does not consider cross-sectoral policy widely enough. A number of alternative integrated policy options are also presented which are proposed to enable greater potential for practical achievement of the government's goals. Ultimately, it is anticipated that an approach which involves much greater integration at domestic (rural-urban development), energy system wide (electric vehicle and decentralized energy integration into the energy supply grid) and regional (co-operation in development of resources in areas of contested ownership) levels, could enhance the energy supply security and stability of the region as well as Japan itself.
\end{abstract}

Key words: Japan; Fukushima; nuclear; renewable energy; scenarios; integrated policy; 


\section{Introduction}

The precarious pre-Fukushima community support for nuclear power in Japan has been undermined by the disasters of 2011, and a significant rethink of the energy strategy into the future has been prompted. The Japanese government proposed (in June, 2011) three alternative energy mix scenarios for public consultation [1] after which (in September, 2011) it selected the zero nuclear power option as its preferred scenario - potentially overturning around 50 years of pro-nuclear policy. As this is yet to be formalized in national policy and the outcome of the next national election (December 2012) may change the proposed scenario, we examine all three options in this study as well as looking more broadly at the possibilities and limitations that alternative strategies may entail.

By way of background, this section will examine firstly the current perspectives postFukushima on the implications and potential way forward for Japan, before addressing specifically the government's latest proposals. The current boundary conditions are that despite previous policies seeking greater energy security, energy supply in Japan is $96 \%$ dependent on overseas imports [2], and the price of energy resources is still increasing in international markets [3]. The domestic $\mathrm{CO}_{2}$ emissions in Japan have increased by $20 \%$ compared to 1990 levels in the electricity generation sector up to 2009 [4] despite commitments to emissions reductions. On the other hand, the present potential of renewable energy is constrained by cost, production rates and system integration challenges [5].

The overall aim of this paper, beyond the assessment of the proposed scenarios, is to highlight key areas needing action, alternative or complementary strategies that could successfully achieve the social, economic and environmental goals of Japan. To do this, we draw on background theory in energy systems modeling and design, as well as sustainability and resilience - which have been used previously to demonstrate some of the strengths and weaknesses of alternative energy systems and technologies [6, 7]. The paper first examines the pre-Fukushima energy policy in Japan and the changes that have been made due to the accident. The proposed government scenarios are then analysed from the perspective of feasibility, using energy system modeling, followed by an analysis of the potential implications and likely achievement of outcomes. Finally, some alternative integrated approaches are suggested that may improve the outcomes across the energy planning period. 
To put the paper within the context of recent literature, Japan's energy policy has long been of interest, due to the limited resources and the government's response to various energy crises [8-10]. Since the Fukushima nuclear accident, there have been a number of studies investigating Japanese energy options from economic [11], energy security [12] and economic / environmental [7, 13] perspectives. However, this current study goes further, in examining both the underlying technical feasibility and the implications for safety and society. Furthermore, it seeks to examine the strategies with regards to both external feasibility and internal consistency, which has not been undertaken elsewhere (to the authors' knowledge).

\subsection{Initial impact of Fukushima on energy policy}

The Fukushima accident prompted an initial reaction from policy makers to disallow any reactors that had ceased operation (whether due to regular maintenance or in response to the earthquake) to restart. The reactors were then required to undertake a "Stress Test" and review to identify whether the power plant would be prepared under similar and foreseeable natural disasters. Additional back-up power supply units were also required. The political and corporate unwillingness to force a decision on the potential restart of reactors, and a number of scandals, for example misconduct by electric power company executives trying to boost support by pushing their employees to attend local community feedback forums, gave national politicians some respite from making the difficult decision of how to proceed. There has also been an ongoing series of accusations and interrogations of leading government and industry figures on their response to the accident and the culture and regulatory mistakes in the preceding years.

For a period of some months most utilities were unwilling to press the issue of nuclear startup any further, and busied themselves with refurbishment of moth-balled thermal plant and purchase of new plant and equipment, as well as securing supply of fossil fuel to cover the lack of nuclear power [12]. The utilities also won the right to increase electricity prices due to the excess cost of fuel (for example in the Kansai area by $11 \%$ for residential and $19 \%$ for larger users [14]).

During the summer of 2011, it was projected that there would be nationwide power deficits due to the lack of nuclear power plants operating in the system. The people of the Tohoku and Kanto regions of Japan endured scheduled black-outs and nationally industry and 
institutions took additional or rescheduled holidays in order to reduce peak energy use. $15 \%$ energy saving targets were set for the whole country - and achieved - with consolidated nationwide efforts (no doubt, also assisted by the widespread and largely unrepaired damage of the earthquake and tsunami and the exodus of large numbers of foreign workers and tourists, and partially due to mild weather conditions) [15].

From the perspective of the anti-nuclear lobbyists, the victory in coping with a summer largely without nuclear power was a strong message that nuclear power was unnecessary. However, on the back of the natural disasters, the imposition of import bans from Japan by other countries concerned about radioactive contamination, the lack of tourists, the increased cost of supplying energy and the energy restrictions, the economy suffered (first trade deficit in over 30 years, largely due to a \$US 58 billion (25.2\%) increase in fossil fuel imports [12]). Long term, despite the naturally decreasing population of Japan, the cost and restricted supply of energy would continue to damage the economy and undoubtedly lead to significant social and industrial damage through loss of employment and competitiveness. At present, although it is very difficult to assess the ultimate impact on Japan's nuclear program, the Japanese government has released the tentative data of economic loss of the nuclear accident and an updated risk cost of nuclear power [16]. Thus the call was renewed by business and industry advocates for the restart of nuclear power plants that had been designated as safe. An additional concern to the utilities may have been that had the nation survived a second summer (this time with no operational nuclear power plants) that the anti-nuclear lobby would have been entirely vindicated. Nonetheless, eventually negotiations between multiple levels of government, Kansai Electric Power Company (KEPCO) and local residents eventually led to the restart of Oi power plant in July 2012 - prompting an improved outlook on energy saving requirements [17].

Further afield, the accident has also had global repercussions for countries considering nuclear power or with operating nuclear power plants - although the reactions have been significantly different. For example, the United Kingdom, France and the United States of America have recommitted to nuclear power [18, 19] while countries such as Germany, Switzerland and Italy have rejected it and others such as China have slowed development [19, 20]. 


\subsection{Recent studies on low-carbon energy systems for Japan}

Since Fukushima has brought the urgency of energy policy consideration back to the forefront of public and academic discussion, a number of examinations of Japan's energy policy and energy supply options have been published - e.g. [12, 21-24]. These papers have raised the potential of largely or entirely renewable energy supplied electricity in Japan. Tsuchiya [22] showed that a mix of $75 \%$ solar and $25 \%$ wind would minimize required storage to balance for instability or demand-generation timing differences, while the optimal supply was $50 \%$ solar, $20 \%$ wind and $30 \%$ other renewables and back-up power. These figures support previous studies indicating that solar-wind power systems with appropriate back-up and storage can provide a significant level of reliability [25]. A number of groups have further examined the potential for $80 \%$ cuts in emissions by 2050 , in line with high-end government targets, which they have shown to be achievable with the retention of nuclear power, and with the substitution of natural gas for nuclear meaning a $65 \%$ cut in emissions would be possible [26]. Others have examined the potential for emissions reductions without carbon capture and storage or nuclear energy, showing potential by 2100 to be approximately $50 \%$ reduction for Japan without these technologies - only a marginal deficit in regards to the government commitments [24].

Without nuclear power, the current emissions per unit of electricity in Japan have already risen by around $11 \%$ and the cost of energy has started to impact on the economy [23]. The question of whether nuclear power can be eliminated from the energy mix is most important to the current policy decisions, but it is a multi-faceted problem and the answer derived can often be traced back to the underlying assumptions. This paper will hereafter analyze the proposed government strategies as a representative set of future options, extrapolating the potential impacts and alternative, synergistic scenarios.

\section{Japanese government strategy}

\subsection{Pre-Fukushima energy policy}

A review of Japanese energy policy indicates that in the five decades prior to the Fukushima nuclear accident, government strategy was based around the following six key drivers:

1. Energy security - particularly reduction of oil dependence (both with regards to the proportion of the energy mix and the sources of supply); 
2. Economic growth and competitiveness - through ensuring cheap supply of energy, restructuring industry and support for domestic companies supplying fuel or technology

3. Reduced environmental impacts - targets and regulations on emissions (initially local pollutants, more recently GHG emissions)

4. Nuclear energy promotion - as a partial solution to import energy dependence and selected environmental impacts

5. Efficient and effective utilization of energy - as a means of maintaining each of the first three points

6. Technology solutions - while some management policies and socio-behavioural policies have been implemented, most of the energy supply and conservation strategies have been technologically based.

These drivers are not mutually exclusive, but highlight the key areas that have absorbed both political focus and investment. The accident at Fukushima has prompted a revision of the energy strategy, but it will be seen that many of these drivers are still in place.

\section{2 "Options for Energy and the Environment"}

In June (2011), the government released a document for discussion, entitled "Options for Energy and the Environment" [1]. This document first introduces the pre-Fukushima energy strategy then presents key guiding principles (discussed in detail in Section 4) and finally three energy scenarios based on different nuclear power development strategies and some analysis of these scenarios. The proposed "viewpoints" and "perspectives" that act as guiding principles all echo previous energy policy, with perhaps two major changes: a focus on decentralization and liberalization of energy supply and on the "green development" strategy that has been adopted elsewhere in the world in recent times. We will return to these points later on in the analysis.

The three scenarios that are presented for the shift in energy mix out to 2030 are outlined in Table 1. The energy mix as of 2010 and the assumed mix in each scenario out to 2030 is shown in Figure 1. One notable deviation from the pre-Fukushima government energy forecast is that each of these scenarios requires around $10 \%$ reduction in overall energy consumption, as opposed to the original plan of $10 \%$ increase. The government predicts each 
of these scenarios to achieve between 15 and $25 \%$ reduction of GHG emissions by 2030 , and to have only minor impact on the economy, although these may largely be attributed to the specific set of assumptions prescribed by the government when it tendered-out the analysis.

Table 1: Outline of the three proposed energy scenarios [1]

\begin{tabular}{|c|c|c|}
\hline & Scenarios & Key points \\
\hline 1 & Zero nuclear power & $\begin{array}{l}\text { - } \text { Rapidly reduce the share of nuclear energy } \\
\text { - } \text { Direct disposal of spent nuclear fuel. } \\
\text { - } \text { Renewable energy and fossil fuels } \\
\text { - } \quad \text { Focus on energy efficiency (also applies to scenarios } 2 \text { and 3) }\end{array}$ \\
\hline 2 & $15 \%$ nuclear power & $\begin{array}{l}\text { - Smooth reduction of dependence on nuclear and fossil fuels } \\
\text { - } \\
\text { - } \\
\text { - Fexrocessing and/or direct disposal of nuclear fuel } \\
\text { in selection of technologies }\end{array}$ \\
\hline 3 & $\begin{array}{c}20-25 \% \text { nuclear } \\
\text { power }\end{array}$ & $\begin{array}{l}\text { - Slowly reduce but maintain dependence on nuclear energy } \\
\text { - New nuclear power plants are required } \\
\text { - Reprocessing and/or direct disposal of nuclear fuel } \\
\text { - Promote reduction of dependence on fossil fuels from an } \\
\text { economic standpoint } \\
\text { - Strong public confidence in nuclear energy and administration } \\
\text { essential. }\end{array}$ \\
\hline
\end{tabular}




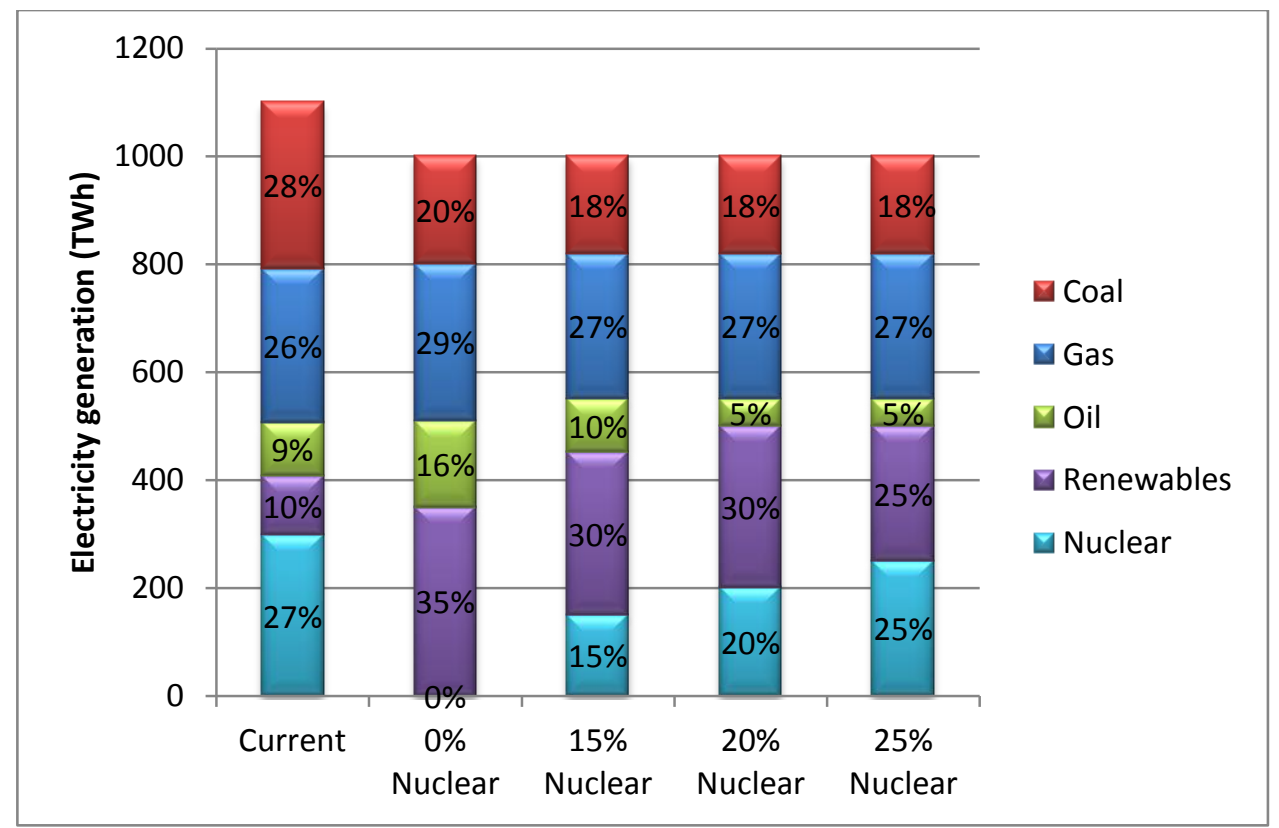

Figure 1: Electricity generation mix in 2030 for the proposed alternative scenarios (after [1])

Examining the required electricity generation under the given scenarios by source (Figure 1) shows that the main constraint in capacity is the renewable energy component - which has to increase its output approximately three-fold in order to fulfill any of the proposed strategies. Coal generation overall will decrease, although there may be replacement of old plants with newer, more efficient ones and gas must expand its output marginally or decrease slightly. Notably, under the government's scenarios, oil usage would increase under the zero nuclear scenario, although this could potentially be replaced by natural gas.

\section{3 "Innovative strategy for energy and the environment"}

Subsequent to the national "deliberative polling" exercise on the "Options for energy and environment", the government released its policy statement the "Innovative strategy for energy and the environment" [27] which highlighted the non-nuclear scenario as the preferred option. This strategy is underpinned by five policy "pillars":

1. Realization of a society not dependent on nuclear power

2. Realization of a green energy revolution

3. Ensuring stable supply of energy

4. Bold implementation of reform of electricity power systems

5. Steady implementation of global warming countermeasures.

As this "Innovative strategy" is effectively a detailed version of the earlier zero nuclear scenario, we will treat it as such in the foregoing analysis, but use the additional detail in the new policy document as a basis for analysis of this particular scenario. 


\section{Evaluation of the proposed scenarios}

In order to clearly understand the implications of these alternative scenarios, in this section we review the options from various perspectives that shed some light on the potential for each scenario to contribute to improved sustainability of the Japanese energy system. These scenarios have been assessed (both in the government's own development process and by independent authors) from the perspective of their theoretical achievability and their impact on greenhouse gas emissions and direct economic performance [1, 28]. Broadly, the scenarios fit within the range of possibility of technologies as presented elsewhere - e.g. [7, $21,25,29,30]$ - however, it is important to highlight some of the constraints and assumptions that must be made in order to achieve the government's proposed scenarios. Thus this section first provides an overview of the constraints on the technological achievability then focuses largely on the outputs and outcomes - specifically identifying weaknesses in other aspects of society and the economy that may or may not be supported by the alternative energy scenarios.

\subsection{Constraints on technical achievability}

Land area is one key constraint in Japan - and in particular, suitable land area for renewable energy (typically diffuse) given that around 66\% of the country is forested, and much of that is mountainous [31]. However, theoretically, covering $20 \%$ of all urban and industrial areas (buildings only, not roads) with PV panels, at a low efficiency of $10 \%$, would be sufficient at average daily insolation [32] to generate the full 350 TWh required from renewables in the government's zero nuclear scenarios (although this must be considered further with regards to the disruption to the grid and matching with demand). Wind power potential has also been demonstrated to be sufficient for more than its required share $[22,25,29]$, while hydropower potential is unable to be expanded significantly as it has already been close to fully-utilized [32].

Beyond the physical limitation, one of the major restrictions on expansion is the limitation in production capacity - the scenarios for 2030 predict an increase of around 20 times the current installed capacity of both wind power and PV. Estimates are that Japan can produce between 4 and $5 \mathrm{GW}$ of PV cells domestically on an annual basis, making the PV target achievable (if the entire domestic production is put to use domestically), while the wind 
turbine purchase or production and installation potential is also estimated to be viable (see Table 2). Therefore the technical limitation is found to be consistent, although it may stretch the limits of capacity. Auxiliary equipment limitations such as batteries and transmission lines are not included, which is likely to make the scenarios a little less easy to achieve.

Table 2: Renewable energy potential in Japan [30]

\begin{tabular}{|c|c|c|c|}
\hline Source & Potential & Capacity Factor & $\begin{array}{c}\text { Generated electricity } \\
\text { (TWh) }\end{array}$ \\
\hline Hydro & $21 \mathrm{GWe}$ & $35 \%$ & 64 \\
\hline PV & $100 \mathrm{GWp}$ & $12 \%$ & 105 \\
\hline Wind & $100 \mathrm{GWp}$ & $20 \%$ & 175 \\
\hline Biomass & $2 \mathrm{GWe}$ & $50 \%-90 \%$ & 12 \\
\hline
\end{tabular}

GWe: Gigawatts Electricity, GWp: Gigawatts Peak

Maintaining nuclear power in the mix, under the $15 \%$ and $20 \%$ scenarios is also an important technical consideration. One of the exacerbating factors in the safety of nuclear power in Japan particularly is the prevalence of earthquakes. In the Fukushima accident, the subsequent massive tsunami also played a major role in disabling the plant cooling system. We considered two options for achieving the reduction of nuclear power gradually, to enhance safety of the overall system. The first scenario (Option 1) assumes that nuclear power plants are allowed to come back online after passing the newly-legislated safety checks, but that they are retired when they reach their nominal lifetime of 40 years. The second scenario (Option 2) assumes that on top of the rules for Option 1, no nuclear power plants situated on the pacific coast (where the potential for large tsunamis is greater than on the Japan Sea coast) are allowed to return to operation. Both scenarios assume that the government's planned reduction in electricity demand from 1.1 to 1 trillion TWh is achieved linearly from 2012 onwards through to 2030. Assuming that the second scenario applies to existing plants, but that all currently proposed plants are constructed close to schedule (for plants on the Japan Sea coast) would give Option 3. The government's "Innovative strategy" [27] would effectively involve the choice of Option 1 or Option 2.

In order to plot the graphs under these options, the data on nuclear power plant construction dates (historical and proposed) and the nominal generating capacity was obtained from 
elsewhere (e.g. [33]), and a simple correlation to the 40 year lifetime was applied. The resulting installed capacity and percentage contribution to electricity supply for the three options are shown in Figure 2 (assuming a constant capacity factor equal to the existing nuclear fleet $)^{2}$. This shows that a conservative approach to reducing nuclear power risk over a 20 year period would lead to the government's proposed $15 \%$ scenario being achieved. The $20-25 \%$ scenario could only be achieved by either allowing the operation of plants beyond their 40 year lifetime, by allowing new construction on the Pacific coast, or by accelerating the construction of new plants. In order to naturally reduce the nuclear power generation to zero, the time period would be need to be extended out to beyond 2040 .

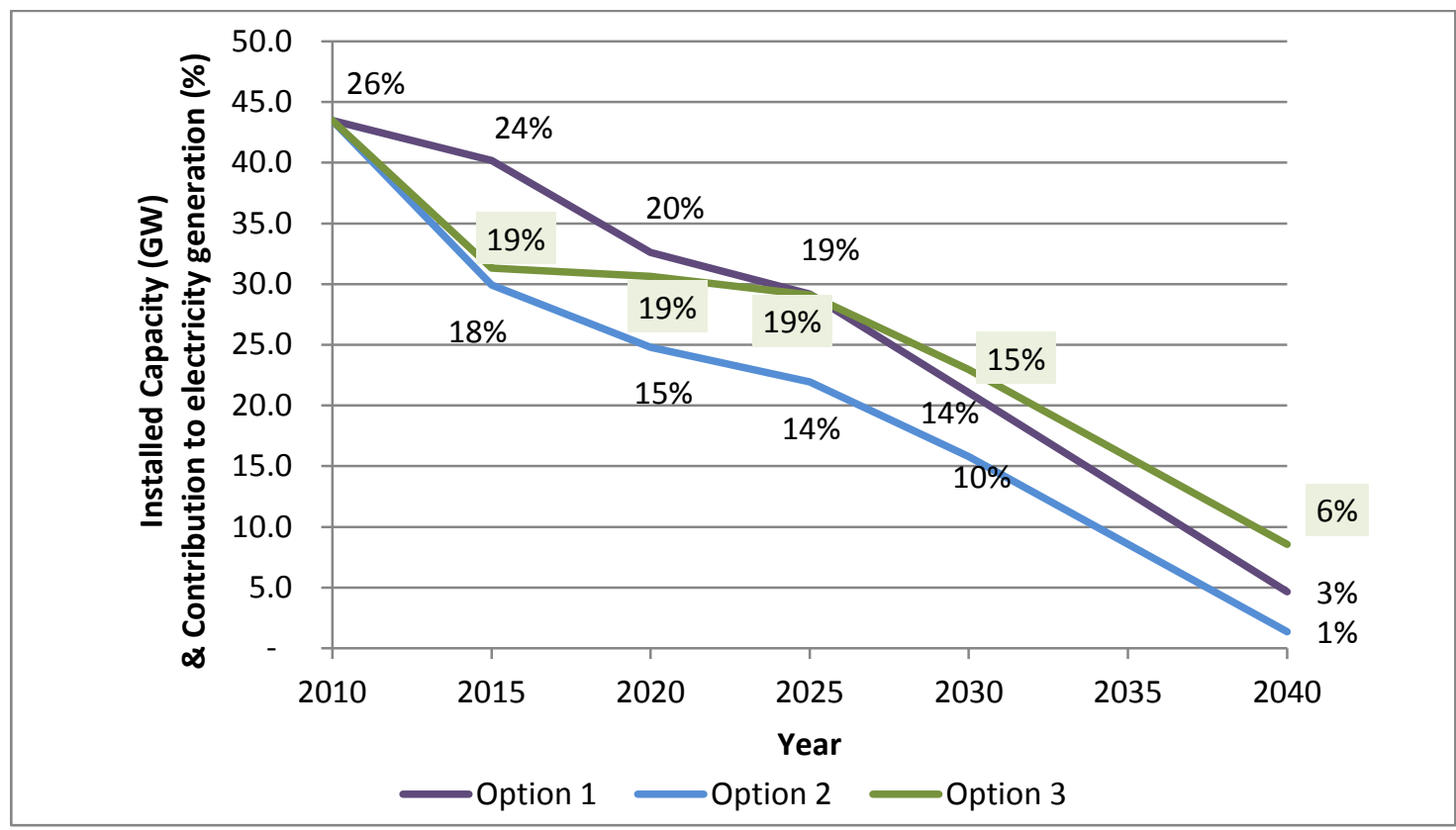

Figure 2: Natural phase-out of nuclear power installed capacity and contribution to electricity generation (\%)

One key aspect not shown in this graph is the uneven distribution of nuclear power plants that would be decommissioned under the proposed options. In the Tokyo, Chubu and Tohoku Electric Power Company jurisdictions, most of the power plants would be shut down particularly in Option 2 and 3 - which would lead to an uneven distribution in power deficit due to the lack of interconnection between the western and eastern electricity grids.

\subsection{Potential outcomes - Safety}

In the proposed electricity system scenarios, the nuclear power safety was evaluated using the dependence ratio on nuclear power in the energy mix as the only metric. Notwithstanding the

${ }^{2}$ The TWh produced per GW capacity is therefore equal across the period, and the TWh produced from nuclear power plants divided by the total TWh electricity produced is the percentage contribution to total electricity. 
progress in nuclear energy safety and the critical importance of geographic distribution, this is perhaps a reasonable indicator. However, nuclear power safety must ultimately cover more than just the generation of electricity - the remainder of the fuel cycle, and the decommissioning of current facilities is also important. At present, there is approximately 20,000 tonnes of spent nuclear fuel stored inside nuclear power plants or interim storage facilities in Japan [34]. The management and disposal of the spent nuclear fuel requires nuclear power experts, various advanced technologies and significant financial support. While the government scenarios acknowledge this in the "three viewpoints", if nuclear power is to be phased out, it will require a concerted effort to encourage and maintain the level of skills and knowledge required for the task of maintaining nuclear waste safety. This necessity is highlighted in the "Innovative strategy", with a government commitment to promoting research and development on reprocessing as well as a consultative process to find an appropriate storage place for spent fuel [27].

\subsection{Potential outcomes - Energy Security}

Renewable energy provides the only major potential for domestic energy security in Japan. Therefore, the use of the largest possible share of renewables in Japan is the only option that can lead to energy security in a "pure" sense of the term, while the use of nuclear power and the ownership, control or contracted purchase of foreign resources and companies may constitute secondary options (but under a compromised definition of energy security).

Apart from renewable energy, the proposed scenarios will continue to require imports of fossil fuels - slightly less gas in all scenarios, much less coal and a range of around $+/-50 \%$ in the rate of oil consumption (greater for the lower nuclear scenarios). If oil is phased out, then the increase in natural gas consumption will be equivalent to around $50 \%$ of current consumption. Japanese companies have recently been taking majority shares in many LNG projects globally, and have large shares in coal resources in countries such as Australia, fitting the secondary definition of energy security. The availability and cost of gas are likely to improve through the expansion of shale gas production in the United States. It is arguable that a diverse portfolio of energy sources and generation options is likely to improve the resilience of the energy system in case of disaster; however, the level of dependence on imported resources would ideally be as low as possible [6]. 
If a $30-35 \%$ share of renewables in total electricity generation is achieved, then the level of energy dependence will certainly decrease - although perhaps only to around $85 \%$ of energy being imported. Without a major move away from fossil fuels (especially oil) in other sectors, the energy security problem will still remain as a significant vulnerability.

\subsection{Potential outcomes - Environment}

In the published three scenarios, $16-25 \% \mathrm{CO}_{2}$ emission reductions was claimed to be realized in the whole power generation system [1], however applying two alternative models (one static model based on the proposed total generation by source, and one hour-by-hour simulation [30]) this was not reproducible - thus it is assumed that the government is relying on a significant amount of offsetting from investment in overseas clean development mechanism projects to earn emissions reduction credits. Using advanced, highly efficient fossil fuel technology, the $0 \%$ scenario cannot reduce $\mathrm{CO}_{2}$ emissions compared to the 290 million tonnes that represent the 1990 level as shown in Table 3. This is apparent even when we compare the phase-out of all oil-based generation and its substitution with natural gas. The only way that reductions could be achieved in this scenario is to introduce a significant level of carbon capture and storage (CCS). CCS is not yet fully-proven, and there is little indication of its technical feasibility or public acceptability in Japan as yet, so it is unlikely to be a near-term solution. The $15 \%$ scenario is only a marginal improvement, while the $20-25 \%$ nuclear scenarios may achieve around $15 \%$ reduction in emissions. Thus, it would appear unlikely that the environmental benefits (at least on the global warming metric) would be significant.

Table 3: $\mathrm{CO}_{2}$ emissions in the power generation sector in the three scenarios

\begin{tabular}{|c|c|c|c|c|c|}
\hline \multirow{3}{*}{ Scenario } & \multicolumn{5}{|c|}{$\mathrm{CO}_{2}$ Emissions (Million Tonnes) } \\
\hline & \multirow{2}{*}{$\begin{array}{c}\text { Reference } \\
\text { (1990) }\end{array}$} & \multirow{2}{*}{$0 \%$ Scenario } & \multirow{2}{*}{$15 \%$ Scenario } & \multicolumn{2}{|c|}{$20-25 \%$ Scenario } \\
\hline & & & & $20 \%$ & $25 \%$ \\
\hline Dynamic model & \multirow{3}{*}{290} & $322(+11 \%)$ & $282(-3 \%)$ & $246(-15 \%)$ & $238(-18 \%)$ \\
\hline Static model & & $330(+14 \%)$ & $275(-5 \%)$ & \multicolumn{2}{|c|}{$246(-15 \%)$} \\
\hline Static model (no oil in mix) & & $290(-0 \%)$ & $243(-14 \%)$ & \multicolumn{2}{|c|}{$233(-20 \%)$} \\
\hline
\end{tabular}


From the perspective of natural resources, the requirement for rare metals, rare earth metals and other materials would increase. For example, it has been estimated that around $15 \%$ of rare earth-based permanent magnets are used in wind turbines and another $15 \%$ in automobiles [35] - a switch to higher use of electric vehicles, hybrids and wind power would require increased usage of such materials, with production having been limited in recent years due to Chinese export restrictions. Though spaced out over a period of 15-20 years, the availability of these key materials may be a restricting factor (physically or economically) on achieving the government energy scenarios.

\subsection{Review from the Social Perspective}

From the perspective of benefit or impact on society, the scenarios hold variable and uncertain potential. We will consider here a number of potential areas of impact - the potential to impact on quality of life, the change in industry structure and subsequent employment implications.

In 2005 there were approximately 10,570 employees in the nuclear industry in Japan [36]. While this is not perhaps excessively large (only $0.016 \%$ of the total labor force), it represents $3.1 \%$ of all employees in the "electricity, gas, heat supply and water" sector [37]. Reducing this direct source of employment, as well as the flow-on jobs in local communities would be expected to have a mild negative impact nationally, but an acute impact locally. Likewise, the additional loss of jobs in coal-fired power plants would negatively impact. These reductions may be made up elsewhere in the energy industry or in manufacturing expansion to produce and install the needed infrastructure for renewable energy, but the balance is uncertain. It is apparent that most renewable energy technologies do not employ high numbers of people in their operational phase (geothermal and biofuels being exceptions), but there could be significant boost during the construction period [38]. If the technologies being promoted most widely were geothermal and biofuel, the job losses may not be as significant, as the labor intensity in generation is close to equivalent with other thermal technologies such as coal and nuclear (especially when the mining of fuel does not occur locally).

Quality of life (QoL) is difficult to measure effectively, or to estimate on the scale of a country without going into excessive detail. The "Human Development Index" of the United 
Nations Development Program [39] utilizes Gross National Income (GNI) per capita as a proxy for QoL, although here by way of example we use the similar indicator GDP which was the initial indicator used in the HDI, although it is certainly the subject of criticism [40]. It is likely that, with no significant shift in fertility rates or immigration policy, the population of Japan will have declined by around 9-12 million people from its current level of 127.8 million [37, 41]. Under the government's tendered modeling [1], the zero nuclear scenario produces a lower increase in real GDP over the period, but still enables growth - hence all scenarios (using total real GDP / population as the indicator) would indicate an increase in quality of life.

On a direct scale, electricity costs account for approximately $3.3 \%$ of total monthly household expenditure, with energy in total accounting for around 5.7\% [37]. Not including the potential for natural gas costs to increase, if the cost of electricity to residential users is to approximately double (as shown in the government modeling), then household energy usage will account for around $9 \%$ of expenditure, with $6.6 \%$ being due to electricity. This direct impact may be reduced somewhat through the improvement in efficiency that is being sought - and it has been demonstrated that at least $15 \%$ is achievable without new technology. The cost of "embodied energy" in domestically produced goods and services may however, impact more dramatically.

\section{Analysis of internal consistency}

The potential outcomes and indicators of achievability that were addressed in the previous section are important factors in determining the overall value of the proposed government scenarios. However, it is also important to examine whether the proposed scenarios are internally consistent. In particular, the government's "Options for Energy and the Environment" puts forth "three viewpoints to promote drastic energy structure reforms that need to be addressed whatever options are chosen" and "four important perspectives in choosing energy options" [1] (refer Table 4 and Table 5). These "viewpoints" and "perspectives" were used as an empirical tool for comparing the internal consistency of the alternative scenarios proposed. The resulting analysis is discussed below. 
Table 4: The "three viewpoints" laid out by the government [1]

\begin{tabular}{|c|c|}
\hline \multicolumn{2}{|c|}{ Three viewpoints to promote drastic energy structure reforms } \\
\hline \multirow[t]{3}{*}{$\begin{array}{l}\text { 1. Shifting to clean energy sources and securing } \\
\text { green growth }\end{array}$} & $\begin{array}{l}\text { a. Shift the energy structure to renewable energy, clean energy (hydrogen and storage } \\
\text { system, etc.), and energy conservation }\end{array}$ \\
\hline & $\begin{array}{l}\text { b. Promote consumption and investment, and accelerate green innovation and investments } \\
\text { in next-generation energy networks while sharing ambitious goals (increasing the share of } \\
\text { renewable energy to over } 25-30 \% \text { and reducing energy consumption by } 10 \% \text { from current } \\
\text { level by 2030) }\end{array}$ \\
\hline & $\begin{array}{l}\text { c. Draw up the Framework for Green Development Policy and promote regulatory reform } \\
\text { and support for development in an integrated manner, and use them as the basis of } \\
\text { Japan's revival. }\end{array}$ \\
\hline \multirow[t]{2}{*}{$\begin{array}{l}\text { 2. Reforming the energy system led by } \\
\text { demand side actors }\end{array}$} & $\begin{array}{l}\text { a. Convert to a new distributed energy system under which each citizen can choose their } \\
\text { own energy sources as a consumer / producer. }\end{array}$ \\
\hline & b. Implement energy / electric power systems reform as a priority area. \\
\hline \multirow[t]{2}{*}{$\begin{array}{l}\text { 3. Multifaceted international contribution } \\
\text { for energy and the environmental field. }\end{array}$} & $\begin{array}{l}\text { a. Converting structures toward clean energy development and further innovation in energy } \\
\text { efficiency will serve as a basis for Japan to share its challenges with emerging countries } \\
\text { and to promote multifaceted international contribution in the fields of energy / the } \\
\text { environment. This will also offer a model for solving global warming. }\end{array}$ \\
\hline & $\begin{array}{l}\text { b. In light of the experience of the TEPCO Fukushima Nuclear Power Plant accident, Japan } \\
\text { will fulfill its responsibility as a country using nuclear power for peaceful purposes by } \\
\text { controlling nuclear power risks, improving nuclear safety, undertaking decontamination, }\end{array}$ \\
\hline
\end{tabular}


c. Share our experiences in and lessons learned from the accident with other countries.

Table 5: The "four important perspectives" proposed by the government [1]

\section{Four important perspectives in choosing energy options}

1. Securing nuclear safety and reducing future risks (The current prime challenge is to secure social safety and security in a sustainable manner)

\section{Strengthening energy security}

(Amidst the uncertainty in the global energy situation and the prospects for securing alternative energy, strong demand for energy security remains unchanged.)

\section{Contributing to the solution of global} warming

(Efforts to reduce domestic $\mathrm{CO}_{2}$ emissions must be continued in the course of carrying out measures to reduce dependence on nuclear energy.)

\section{Restraining costs and preventing hollowing-} out of industry.

(Efforts should be made to avoid the situation where industry and employment are hollowed-out as a result of the energy mix conversion) a. By minimizing risk through the implementation of thorough safety measures and reducing the amounts of spent nuclear fuel and radioactive waste, the burden on future generations should be reduced. At the same time, technologies and human resources for ensuring nuclear safety need to be secured and developed.

b. Based on the above, a roadmap to reduce dependence on nuclear energy needs to be framed.

a. The roadmap to reduce dependence on nuclear energy needs to be framed in a form that is compatible with both energy security and the diversification of energy sources.

a. The current goal for the reduction of greenhouse gas emissions includes sinks and those gained through international contributions in addition to the reduction of domestic emissions. How should the balance between them be considered?

b. Japan needs to contribute to solving the global warming issue, including reducing $\mathrm{CO}_{2}$ emissions overseas by utilizing Japan's advanced technology.

a. The roadmap to reduce dependence on nuclear energy should be shaped from the perspective of avoiding the hollowing-out of industry and employment as a result of the energy mix conversion, by looking closely into the impact of the increase in energy costs on industry and economy as well as on social changes. 


\subsection{Consistency with the "Viewpoints"}

\subsubsection{Shifting to clean energy sources and securing green growth}

While the scenarios are all relatively consistent in regards to this viewpoint (they all require significant investment in renewables and reduce the overall dependence on fossil fuels), the stated aim of promoting "support for development in an integrated manner" would seem to be lacking in consideration beyond the economic-environmental/energy linkage with renewables. No concrete policies are promoted to integrate across sectors or regions of the economy.

\subsubsection{Reforming the energy system led by demand side actors}

This viewpoint is perhaps the least consistent with the presented scenarios, although it presents a high potential opportunity to bring real market change. Converting "to a new distributed energy system under which each citizen can choose their own energy sources as a consumer / producer" fits well with the promotion of household photovoltaic systems. However, there are severe practical restrictions - such as the large percentage (42\% in 2007) of apartment-type accommodation with neither space nor capacity to install such systems [37]. Furthermore, while market liberalization ${ }^{3}$ has been attempted in the past [42], it has yet to be successfully achieved, and would require particularly strong action to enable residential consumers to have an open choice of energy service provider (currently there is only one electricity provider per major region, and these companies are vertically integrated from generation through to retail).

The other key element to enhance the benefits and potential of these scenarios would be the shifting of the current separated grid system to a single frequency (at present eastern Japan uses a $50 \mathrm{~Hz}$ system and western Japan uses a $60 \mathrm{~Hz}$ system, which prevents easy transfer of energy from one side to the other) [23].

\subsubsection{Multifaceted international contribution for energy and the environmental field}

The apparent need for Japan to claim carbon offsets from overseas in order to come close to achieving its emissions reduction targets is one element of the scenarios that supports this viewpoint. Although there is no solid proposal, perhaps the weakest element of this point is the "controlling nuclear power risks", which may falter under a low nuclear scenario due to a lack of human resources. The scenarios have used the dependence on nuclear energy as the one indicator of nuclear power risk (which is arguably correct), however the remaining nuclear waste and the inevitable decline in nuclear specialists would be a concerning effect driving in the opposing direction.

\footnotetext{
3 "Liberalization" here describes the process of allowing more generators into the electricity sector in order to allow customers the choice of retail electricity suppliers rather than monopoly suppliers as is currently the case - ultimately this is expected to encourage cost competition.
} 


\subsection{Consistency with the "Important Perspectives"}

\subsubsection{Securing nuclear safety and reducing future risks}

Following on from the third "viewpoint", this perspective restates the need for a structured withdrawal from nuclear power and maintaining technology and human resources. To reiterate, the lack of firm policies and financial committment on this is likely to result in the opposite. Moreover, the leading technology edge that Japan has as a supplier of key nuclear technology is likely to suffer and enhance negative GDP effects.

\subsubsection{Strengthening energy security}

Energy security remains an issue for Japan, and despite the enhanced level of renewable energy in the proposed scenarios it is likely to remain a significant issue. However, all of the proposed scenarios will undoubtedly promote greater energy security. One important element of the reduction in nuclear power may be the refocus on energy security as domesticonly energy production rather than the current interpretation that includes nuclear and Japanese-owned foreign resources. This perspective could also be applied to facilitate the acceptance of shared-ownership of disputed territories and resources that are currently causing tensions between China, Japan, Russia and Korea.

\subsubsection{Contributing to the solution of global warming}

As demonstrated, it was found to be unlikely that the proposed government scenarios would reduce emissions by the proposed amounts, thereby leading to the conclusion that significant offshore offsets would be required. It is therefore difficult to say that these scenarios are consistent with this perspective, although with a phasing out of coal and oil, there could certainly be significant progress.

\subsubsection{Restraining costs and preventing hollowing-out of industry}

This perspective is difficult to achieve in reality. Even though the proposal of industry support for expanding renewable energy and energy efficiency may assist, if the price of electricity doubles, many industries will find difficulty in remaining competitive internationally. Already, in previous decades, Japan has seen the off-shoring of energy and labor-intensive industries through government and industry policy decisions [43]. A lack of integrated policy planning is likely to further exacerbate such pressures, as would the likely diminishing of nuclear technology competitiveness. Contrasting with this, is the focus on the technology production side of renewable energy systems, which may prevent the loss of manufacturing industries to some extent. 


\section{Alternative and complementary strategies}

The government's strategies treat the non-energy sector and associated policies as largely separate from the energy scenarios themselves, although they acknowledge the need to shield industry and households from the unwanted impacts and to engage industry in providing the solutions needed. This section examines a number of areas where policy could take an integrated approach, incorporating other sectoral and social concerns. These strategies are not necessarily new, but given the need for a different direction in such a fundamental area as energy, it would be worthwhile even to re-examine such options.

\subsection{Rural renewal and renewable industries}

One of the major social dilemmas that Japan faces (like many modern countries) is the constant process of urbanization leaving rural areas with declining populations, economies and dilapidated infrastructure. Nuclear energy subsidies have been one key element in supporting the infrastructure in such communities, but with the nuclear power phase-out this source of income would be gone. However, when considered from the perspective of selfsufficiency, it is apparent that rural areas are more likely to possess potential for independent and sustainable systems, due largely to lower population density and higher available resource per capita [44]. The lower population density in rural areas would make them prime locations for installation of large renewable energy facilities. In Japan, the "Eco-Model Cities Project" is one wide-scale demonstration that includes a focus on rural cities and may, on a broader scale, be applied to enact an integrated plan for a sustainable Japanese economy [45]. Such an approach would be particularly relevant in areas that have been hardest hit by the natural and nuclear disasters of 2011, which have effectively been given an opportunity for broad-scale remodeling and adoption of the latest approaches to sustainable living.

The use of biomass in energy supply is one attractive model that would boost the economic situation of rural areas. Waste biomass is used widely already. However, there still remains an untapped resource that might offer at least a small energy supply potential [46]. With some estimates that waste forestry products of around 20 million $\mathrm{m}^{3}$ may be available to provide energy [31]. This would be equal to about 156 PJ of thermal energy, or at $35 \%$ efficiency, around 15.2 TWh of electricity - a significant amount if it was collected effectively. However, beyond just waste biomass, it would be feasible for Japan to initiate a sustainable biomass harvesting system, based on tree cropping. An additional synergy in this case is that Japanese cedar pollen allergy is becoming a serious health issue affecting the ability of 
around 25 million people (approximately $20 \%$ of the population) across the country to live and work effectively for two months of the year [47]. This public health issue has arisen largely due to the widespread planting of Japanese cedar post-World War II as building material for construction [47]. By cropping the approximately $40 \%$ of Japanese plantation forests in a sustainable way, while concurrently continuing the reduction of Japanese cedar and other allergenic trees in the mix, a significant synergistic energy and health scenario could be achieved. This scenario would also benefit the economy from higher productivity and lower health costs, as well as assisting in the revival of forestry and subsequently rural areas.

\subsection{Regional partnership and stability}

The third area of integrated strategy for developing a more resilient new energy structure would be to engage in collaborative projects with neighbouring countries. The government strategy focuses largely on implementing Japanese technologies overseas with only a brief discussion on building direct and bi-directional collaboration. The bilateral agreements that have been discussed in the "Innovative strategy" rely on securing resources from fuel producing countries - a strategy that is important, but has also underpinned much of Japan's past energy policy. However, there are apparent opportunities for building both greater security of energy supply and at the same time taking a step towards finally easing tensions between Japan and its neighbours.

Alternative strategies for energy security in Japan have been mooted for many years, but much of this has gained momentum through the advance of technologies such as high voltage direct current (HVDC) transmission lines and expansion of the LNG trade. Some of the major strategies have involved electricity grid connection with the Asian mainland [48] or importing Russian oil and LNG [49]. Most of these strategies suffer from the need for strong cooperation between parties that are currently involved in long term territorial disputes. However, through the government and industry taking a positive step to share resources that are largely the contentious issue regarding such territories, then a mutually-beneficial solution would emerge, which could alleviate energy supply concerns for both Japan and other emerging nations of ASEAN. Japan may be forced to give up or share some of its physical territory, but in exchange could obtain access to greater energy supplies from sub-sea oil and gas deposits or from continental fuel and electricity supply. Ultimately this would also produce a significant vulnerability to international conflicts, but given an associated 
improvement in bilateral relationships the potential provocations are likely to abate to some extent.

\subsection{Integrated energy storage and cross-sectoral emissions reduction}

The final integrated strategy considered here is the expansion of the government's current limited consideration of energy to include other sectors. For example, the transportation sector is the largest consumer of oil, and significant gains could be made through ongoing efficiency, by reducing demand or by switching to alternative energy sources. One example of this cross-sectoral strategy that has been discussed elsewhere is the use of high-efficiency heat pumps for hot water in the residential and commercial sectors, and electric vehicles in the transportation sector as storage for excess electricity [21]. The advantage of such a strategy is that it would enable load shifting and smoothing of the supply curve that has been widely discussed as a limitation for renewable energy. Electricity as the only end-use source of energy may however, be undesirable, as it is likely to introduce excessive vulnerability in the energy system. However, as an opportunity to expand renewable energy use and concurrently reduce emissions across various sectors, it should be explored. Furthermore, Japanese electric vehicle and hybrid vehicle makers have a significant market presence, which could be expanded and provide economic stimulus.

\subsection{Consistency with the "viewpoints" and "perspectives"}

It can be argued that these three (although admittedly general) alternative strategies especially if applied in combination - would be consistent with the viewpoints and perspectives raised by the government. They would explicitly support the shift to clean energy, green growth, reform to engage demand side actors and international collaboration that are the basis of the "viewpoints". Moreover, they would be likely to address the "perspectives" of enhancing energy security, preventing the hollowing-out of industry and contributing to global warming abatement. They do not directly address the issues of nuclear safety and restraining costs, but as complementary strategies, they could add significantly to solutions that make the achievement of these goals possible.

\section{Conclusions}

In this paper we have presented an analysis of the Japanese government's energy scenarios from the stand-point of their achievability and consequences. We have also presented some alternative or complementary strategies that have not explicitly been considered in the government's plans. The Japanese government's post-Fukushima energy plan has tried to shift towards a non-nuclear scenario. However, of the three presented scenarios, the nonnuclear scenario is not necessarily the most likely to succeed in attaining either the safety, 
environmental or economic performance that the country desires. On the other hand, energy security will definitely improve, but is not likely to drop to less than $85 \%$ dependence on imports unless territorial disputes can be solved amicably to obtain rapid access to offshore resources. Integrated scenarios would be likely to provide ultimately more sustainable solutions for energy supply in Japan and Asia generally, although the current limited solutions considered by the government are technically feasible.

\section{References}

[1] National Policy Unit. Options for Energy and Environment - The Energy and Environment Council Decision on June 29, 2012 Tokyo2012.

[2] IEA. Energy balances of OECD countries. Paris, France: International Energy Agency; 2010.

[3] IEA. Energy Price and Taxes, Quarterly Statistics, First Quarter 2011. Paris: International Energy Agency; 2011.

[4] Greenhouse Gas Inventory Office of Japan. The GHG Emissions Data of Japan (19902009). Tokyo2011.

[5] MEJ. Potential for the Introduction of Renewable Energy (FY 2010) [in Japanese]. Tokyo: Ministry of Environment of Japan; 2011.

[6] McLellan B, Zhang Q, Farzaneh H, Utama NA, Ishihara KN. Resilience, Sustainability and Risk Management: A Focus on Energy. Challenges. 2012;3:153-82.

[7] Zhang Q, McLellan BC, Tezuka T, Ishihara KN. Economic and environmental analysis of power generation expansion in Japan considering Fukushima nuclear accident using a multiobjective optimization model. Energy. 2012;44:986-95.

[8] Surrey J. Japan's uncertain energy prospects: the problem of import dependence. Energy Policy. 1974;2:204-30.

[9] Fukasaku Y. Energy and environment policy integration: The case of energy conservation policies and technologies in Japan. Energy Policy. 1995;23:1063-76.

[10] Pickett SE. Japan's nuclear energy policy: from firm commitment to difficult dilemma addressing growing stocks of plutonium, program delays, domestic opposition and international pressure. Energy Policy. 2002;30:1337-55.

[11] Itakura K. Calibrating the Mix of Electric Power Generation Types. In: Kimura F, Shi X, editors. Deepen Understanding and Move Forward: Energy Market Integration in East Asia ERIA Research Project Report 2010-25. Jakarta: Econonmic Research Institute for ASEAN and East Asia (ERIA); 2011. p. 298-310.

[12] Vivoda V. Japan's energy security predicament post-Fukushima. Energy Policy. 2012;46:135-43.

[13] Bhattacharya A, Kojima S. Substitute of Nuclear Energy Supply- A Strategic Policy Decision for Asia. In: Kimura F, Shi X, editors. Deepen Understanding and Move Forward: Energy Market Integration in East Asia ERIA Research Project Report 2010-25. Jakarta: Econonmic Research Institute for ASEAN and East Asia (ERIA); 2011. p. 311-28.

[14] KEPCO. Regarding electricity rate increase. Osaka: Kansai Electric Power Company; 2012.

[15] IEEJ. Japan Energy Brief. In: Kanekiyo K, Ishimura A, editors. Tokyo: The Institute of Energy Economics, Japan; 2011.

[16] Cost calculation council. Cost estimation of various power generation technologies [in Japanese]. Tokyo: National Policy Unit, Cabinet Secretariat, Japan.; 2011. 
[17] Mainichi News. Oi plant's No. 4 reactor starts capacity operation. Tokyo: Mainichi News; 2012.

[18] Wittneben BBF. The impact of the Fukushima nuclear accident on European energy policy. Environmental Science \&amp; Policy. 2012;15:1-3.

[19] Wang Q, Chen X. Regulatory failures for nuclear safety - the bad example of Japan implication for the rest of world. Renewable and Sustainable Energy Reviews. 2012;16:26107.

[20] Wang Q, Chen X. Regulatory transparency - How China can learn from Japan's nuclear regulatory failures? Renewable and Sustainable Energy Reviews. 2012;16:3574-8.

[21] Zhang Q, Tezuka T, Ishihara KN, McLellan BC. Integration of PV power into future low-carbon smart electricity systems with EV and HP in Kansai Area, Japan. Renewable Energy. 2012;44:99-108.

[22] Tsuchiya H. Electricity supply largely from solar and wind resources in Japan. Renewable Energy. 2012;48:318-25.

[23] Huang J, Nagasaka K. The Trends of Japanese Electric Utility Industry under Kyoto Protocol after 311 Earthquake. APCBEE Procedia. 2012;1:199-203.

[24] Okagawa A, Masui T, Akashi O, Hijioka Y, Matsumoto K, Kainuma M. Assessment of GHG emission reduction pathways in a society without carbon capture and nuclear technologies. Energy Economics. 2012.

[25] Esteban M, Zhang Q, Utama A. Estimation of the energy storage requirement of a future 100\% renewable energy system in Japan. Energy Policy. 2012;47:22-31.

[26] Ashina S, Fujino J, Masui T, Ehara T, Hibino G. A roadmap towards a low-carbon society in Japan using backcasting methodology: Feasible pathways for achieving an $80 \%$ reduction in CO2 emissions by 2050. Energy Policy. 2012;41:584-98.

[27] National Policy Unit. Innovative strategy for energy and the environment. Tokyo: The energy and environment council, Government of Japan; 2012. p. 25.

[28] Zhang Q, McLellan BC, Tezuka T, Ishihara KN. Review of Japan's Electricity System Scenarios In Light of Fukushima Nuclear Accident. (Forthcoming); 2012.

[29] Esteban M, Zhang Q, Utama A, Tezuka T, Ishihara KN. Methodology to estimate the output of a dual solar-wind renewable energy system in Japan. Energy Policy. 2010;38:7793802.

[30] Zhang Q, Ishihara KN, McLellan BC, Tezuka T. Scenario analysis on future electricity supply and demand in Japan. Energy. 2012;38:376-85.

[31] MAFF. Annual Report on Forest and Forestry in Japan (Financial Year 2010). Tokyo: Ministry of Agriculture, Forestry and Fisheries; 2011.

[32] Ushiyama I. Renewable energy strategy in Japan. Renewable Energy. 1995;16:1174-9.

[33] IAEA. Power Reactor Information System. Paris: International Atomic Energy Agency; 2011.

[34] Katsuta T, Suzuki T. Japan's spent fuel and plutonium management challenge. Energy Policy. 2011;39:6827-41.

[35] Du X, Graedel TE. Global In-Use Stocks of the Rare Earth Elements: A First Estimate. Environmental Science \& Technology. 2011;45:4096-101.

[36] JAIF. Nuclear Industry Survey Report. Tokyo: Japan Atomic Industrial Forum; 2007.

[37] MIAC. Japanese Government Statistics. Tokyo: Statistics Bureau, Director-General for Policy Planning \& Statistics Research and Training Institute; 2012.

[38] Moreno B, López AJ. The effect of renewable energy on employment. The case of Asturias (Spain). Renewable and Sustainable Energy Reviews. 2008;12:732-51.

[39] Klugman J. The Real Wealth of Nations: Pathways to Human Development. Human Development Reports. New York: United Nations Development Programme; 2010. 
[40] Sagar AD, Najam A. The human development index: a critical review. Ecological Economics. 1998;25:249-64.

[41] Kaneko R, Ishikawa A, Ishii F, Sasai T, Iwasawa M, Mita F, et al. Population Projections for Japan: 2006-2055 Outline of Results, Methods, and Assumptions. The Japanese Journal of Population. 2008;6:39.

[42] Takase K, Suzuki T. The Japanese energy sector: Current situation, and future paths. Energy Policy. 2011;39:6731-44.

[43] Perkins FC. A dynamic analysis of Japanese energy policies: Their impact on fuel switching and conservation. Energy Policy. 1994;22:595-607.

[44] Tsuda K, Hara K, Uwasu M. Designing Supply-Demand Relationships of Food and Renewable Energy towards Ensuring Regional Sustainability: Case Study of Shinjo Village, Okayama, Japan. In: Matsumoto M, Umeda Y, Masui K, Fukushige S, editors. EcoDesign 2011 - 7th International Symposium on Environmentally Conscious Design and Inverse Manufacturing. Kyoto, Japan: Springer; 2011. p. 11-4.

[45] PCLCC. Eco-model city project - sustainable city for future. Tokyo: Promotion Council for the Low-Carbon Cities; 2012.

[46] Minami E, Saka S. Biomass resources present in Japan--annual quantities grown, unused and wasted. Biomass and Bioenergy. 2005;29:310-20.

[47] Okuda M. Epidemiology of Japanese cedar pollinosis throughout Japan. Annals of allergy, asthma \& immunology : official publication of the American College of Allergy, Asthma, \& Immunology. 2003;91:288-96.

[48] Kanagawa M, Nakata T. Analysis of the impact of electricity grid interconnection between Korea and Japan-Feasibility study for energy network in Northeast Asia. Energy Policy. 2006;34:1015-25.

[49] Phillips J, Challacombe J. Is Russia a viable oil source for Japan? Energy Policy. 2003;31:837-47. 


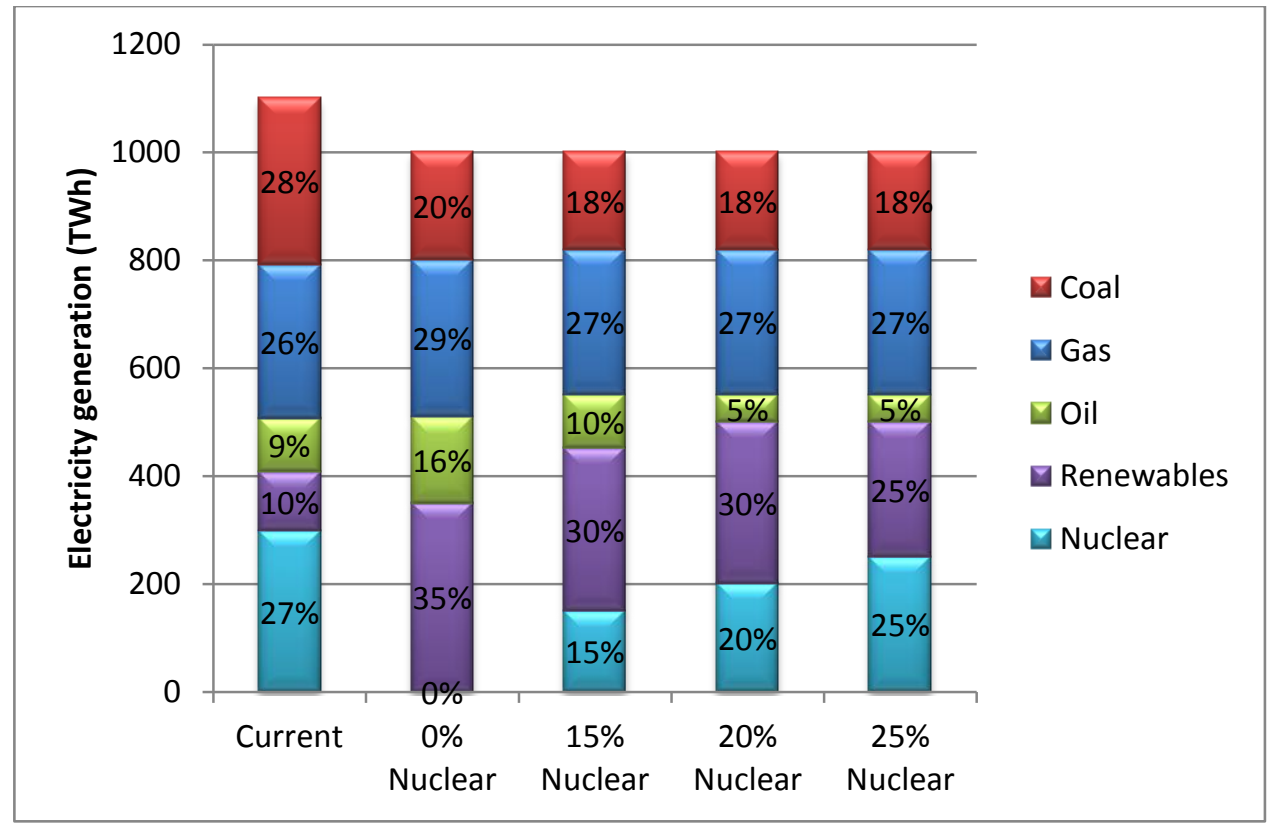

Figure 1: Electricity generation mix in 2030 for the proposed alternative scenarios (after [1]) 


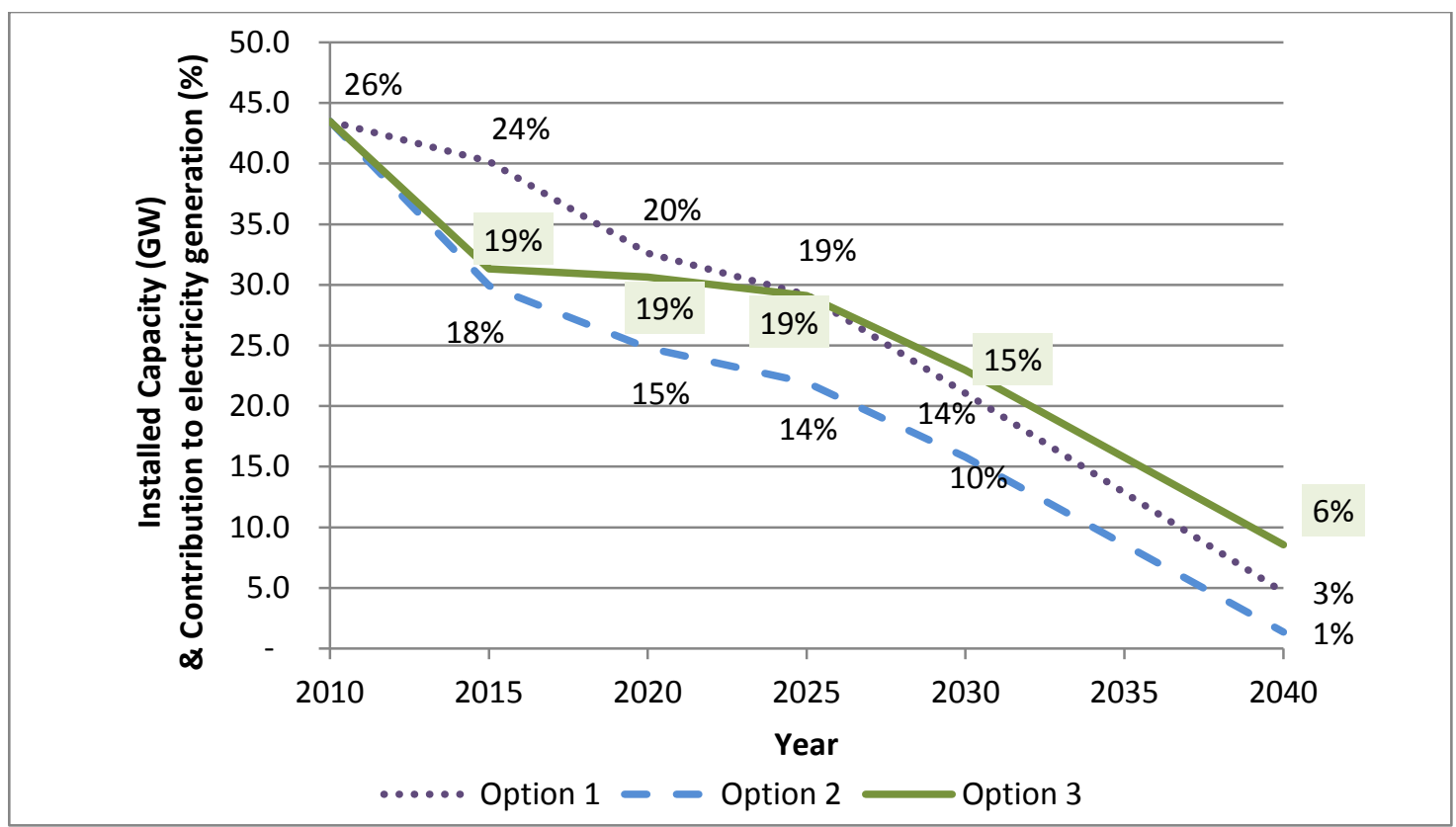

Figure 2: Natural phase-out of nuclear power installed capacity and contribution to electricity generation (\%) 